\title{
ENSINO DE PÓS-GRADUAÇÃO EM MEDICINA TROPICAL
}

\author{
J. Rodrigues Coura*
}

\section{INTRODUÇÃO}

Inicialmente devemos conceituar "Medicina Tropical" antes de analisar os objetivos do Ensino de Pós-graduação nessa área, de concepção tão vasta e abrangente. Senso amplo, Medicina Tropical seria toda aquela desenvolv:da no sentido de promover a saúde, prevenìr e controlar a doença e sua evolução e planejar a vida nas regióes intertropicais. Esta concepção, entretanto, de tão vasta impediria a adoção da Medicina Tropical como uma especialidade médica e, portanto, não haveria como aperfeiçoar especialistas na medicina inteira.

o conceito de medicina tropical como especiatidade médica varia consideravelmente de acordo com o enfoque ou necessidade operacional de cada Pais ou regiño. Assim, na maioria dos paises europeus e mesmo nos Estados Unidos da América do Norte, a chamada Medicina Tropical praticamente se confunde com a parasitologia e com a entomologia, com alguma ênfase na epidemiologia das doenças parasitárias, porém com atividade clínica especializada bastante reduzida. O trato das doenças infecciosas e parasitárias, ou melhor, dos doentes ou portadores dessas doenças, fica a cargo do clinico geral, na maioria das vezes não especializado. Este fato temos observado ao longo de nassa carreira, em congressos, visitas e cursos realizados no exterior, particularmente durante a viagem de observação que tivemos a oportunidade de realizar em 1969, quando visitamos 17 Instituiçóes que ministram cursos de Pós-graduação em Medicina Tropical, 14 delas na Europa Central e 3 nos Estados Unidos da América. Estes cursos, alguns de curta duração de 3 a 4 meses, como os de Liverpool, Hamburgo e Paris, outros de duraçâo mais longa, de 9 a 11 meses, como os de Londres, Antuérpia e o da Tulane University nos EUA, são basicamente cursos de parasitologia e entomologia, com noções de epidemiologia e informações clinicas sobre a patologia tropical na área das doenças infecciosas e parasitárias.

No Brasil, de alguns anos para cá, precisamente após a morte de Evandro Chagas, vem se criando uma tradição extremamente prejudicial ao desenvolvimento da Medicina Tropical, qual seja a triplice separação entre "Tropicalistas clínicos", parasitologistas e uma espécie de sanitaristas de gabinete, na qual os chamados "Tropicalistas" de formação clínica pouco conhecem de parasitologia, de entomologia, de microbiologia e de patologia básica, além de uma fraca formação epidemiológica sobretudo no que se refere à moderna epidemiologia quantitativa, que exige conhecimentos fundamentais de matemática e estatística.

* Departamento de Medicina Preventiva, Faculdade de Medicina da Untversidade Federal do Rlo de Janeiro. Conferéncla pronunciada no $X$ Congresso da Sociedade Brasileira de Medictna Tropical, Curitiba, 3-6 de fevereiro, 1974. 
Por outro lado os parasitologistas, entomologistas e patologistas têm noções muito rudimentares de epidemiologia e clinica das doenças infecciosas e parasitárias. Os sanitaristas, de formaçâo bem mais eclética, perdem-se hoje nos meandros administrativos dos gabinetes, de um lado devido ao seu pequeno numero $e$ à enorme exigência "documental" dos intermináveis relatórios e planos inexequíveis, e de outro lado pela formação em Escolas de Saúde Pública isoladas do campo de trabalho, tornando-se extremamente teóricos ou excessivamente timidos, após uma vida executando programas que náo lhes permitem uma avaliação criteriosa do seu trabalho. Näo vejam as senhores nestas palavras nenhuma critica ao "Sanitarista brasileiro", mas ao sistema atual de formação $e$ aproveitamento desses "heróis" que, resistindo ao desestimulo do Serviço Público, ainda se enchem de entusiasmo quando se thes acenam com um plano exequivel e promissor em termos de realização de trabalho.

Em nosso meio, Medicina Tropical deve ser o tipo de atividade médica desenvolvida por profissionais com sólida formação clínico-epidemiológica, sobretudo no campo das doenças infecciosas e parasitárias e com ampla base de ecologia, parasitologia, entomologia, microbiologia, imunologia e patologia, capazes de planejar corretamente uma investigação epidemiológica de campo, estabelecer um diagnóstico clínico e o tratamento adequado de uma doença infecciosa ou parasitária, podendo utilizar-se das técnicas das sub-especialidades básicas mencionadas para confirmação diagnóstica e investigação num determinado ramo em que venha a especializar-se. Não queremos com isto dizer que o "Tropicalista" seja um especialista em todas as coisas, mas que venha a preencher compreensivamente a enorme lacuna entre o hospital e o campo ,entre o laboratório e a clinica das doenças infecciosas e parasitärias, com os seus muiltiplos aspectos jamais atendidos integralmente por especialistas de sistemas como pneumologistas, cardiologistas, neurologistas etc., sem a necessária base parasitológica, microbiológica e epidemiológica e nem tão pouco por microbiologistas e parasitologistas sem a necessária formação clínica. Medicina Tropical é uma especialidade peculiar de atividade de campo, hospitalar e laboratorial, ponto de junção entre a clínica, a parasitologia, a microbiologia, a patologia e o meio ambiente.

\section{POS-GRADUAÇAO E DESENVOLVIMENTO}

A pós-graduação é quase tão antiga quanto a própria Universidade; assim, - primeiro grau acadêmico conhecido foi conferido pela Universidade de Bolonha em meados do século XII (Doutorado, do latim "Docere"), quando existiam apenas 5 Universidades na Europa: a de Salermo e a de Bolonha na Itália; a de Montpellier e a de Paris, na França $e$ a de Oxford na Inglaterra. A "licencia docenti" era conferida inicialmente pelos Cardeais que permitiam ou não a abertura de outras escolas além da Catedral; em estágio posterior, a licença para ensinar era outorgada mediante um exame formal onde se avaliava a capacidade e a vocação do candidato a professor. A figura dos "Guias de Mestres" foi a primeira representação livre da supervisão eclesiática para a concessão das licenças. As grandes Escolas como as de Paris e Bolonha proclamavam-se Centros de Excelência e a um Doutor dessas Escolas era permitido ensinar praticamente em qualquer lugar. A Universidade Européia atingiu o seu apogeu durante os séculos XIII, XIV e XV sob a supervisão eclesiástica.

O conflito religioso do século XVI iniciado na Alemanha causou uma verdadeira revolução universitária, levando-a ao caos e ao descrédito. A criação da Academia de Berlim e da Royal Society na Inglaterra e a recusa de Leibnitz em aceitar uma Cadeira em qualquer Universidade alemã, bem como a retirada da educą̧āo dos nobres da Universidade na França e na Alemanha, demonstravam a decadência universitária. O protestantismo de Martin Luther não conseguiu deslocar por completo a influência da Igreja ortodoxa no ensino, porém abalara 
as suas bases a tal ponto que a Universidade alemä entrou numa fase de extrema inquietação, culminando com a criação das novas Universidades de Halle, Göttingen e Berlim - berço de uma nova cultura científica e filosófica - cuja expressão mais pura encontramos em Wilhelm e Alexander von Humboldt. A Inglaterra reviveu a Universidade de Cambridge através dos trabalhos de Sir Isaac Newton e da crescente atenção às ciências matemáticas e físicas nos ültimos anos do século XVII. Estava assim restabelecido o prestígio científico da Universidade e uma nova era se abria num progresso constante até os dias em que vivemos.

o sistema de pós-graduação organizado teve como berço a Universidade alemã e valeu a esse País a liderança cientifica e tecnológica durante quase um século até a II Guerra Mundial. Esse sistema, adotado pela Universidade americana, inicialmente na Yale University, que conferiu em 1861 o primeiro PhD nos moldes das grandes Universidades germânicas, atingiu o seu pleno desenvolvimento na Universidade de John Hopkins, que se instalou em 1876, voltada especialmente para a pesquisa e para o ensino de graduados, deflagrando o grande impulso da Universidade americana e de sua área de influência, a tal ponto que um grande numero de paises passou a mandar os seus graduados para aperfeiçoarem-se naquele Pais, vários paises passando a imitar o seu sistema de pós-graduação, entre os quais mais recentemente o Brasil. O sucesso inconteste da Universidade americana e do seu sistema de pós-graduação deve-se, a nosso ver, a uma implantação realista do tipo empresarial, voltada para as necessidades da comunidade e utilizando-se dela como fonte de recursos para a manutenção dos altos padrões da ciência e da tecnologia, o que, em ültima análise, reverte como fonte de riqueza num mecanismo de re-investimento ComunidadeUniversidade-Empresa-Comunidade.

A universidade brasileira, de concepção medieval embora de implantaçāo recente, não encontrou ainda o seu caminho. O salto econômico do nosso Pais, ora em curso, está sendo assistido pela Universidade brasileira, mas não está sendo por ela acompanhado em sua plenitude. Urge um despertar realista para que a projetada riqueza deste Pais seja acompanhada da grandeza de suas Universidades, fonte perene de inspiração e liderança.

Fala-se muito hoje em dia no "Ensino por Objetivos" e na "Universidade Empresa", terminologia de alto conteúdo dinâmico, porém que não encontra ressonância prática pelo menos no estágio atual de nossas Universidades, de infraestrutura extremamente frágil e perspectivas financeiras limitadas a curto prazo. É óbvio que o planejamento programático é do mais alto interêsse; entretanto, se não firmado numa infra-estrutura adequada, ele cairá fatalmente no vazio, sobretudo agora com a velocidade das transformaçóes de nossa Sociedade. $\mathbf{t}$ urgente que encaremos o sistema educacional na base de sua infra-estrutura operacional e não apenas no seu conteúdo programático, do contrário seremos os eternos "filósofos da educação", um verdadeiro exército de "Brancaleones". Louvamos o grande esforço do atual Governo em estimular a Universidade $e$ todo o sistema educacional brasileiro, inclusive mais recentemente o de pós-graduação, entretanto vemos ainda muito distante o fruto deste esforço, pelo menos no setor universitário, onde uma estrutura pobre e arcaica se debate meio trôpega, de um lado com a massificação do ensino de graduação $e$, do outro, com a exigência da formação de uma elite científico-cultural de pós-graduados, função para a qual, temos de reconhecer, a Universidade brasileira não está devidamente preparada.

Acreditamos na Universidade como empresa, mas é necessário que o crédito seja dado como um alto investimento e a longo prazo e que o Governo, a Sociedade, os professores e alunos, não esperem dele um resultado imediato e invistam na sua infra-estrutura sem acanhamento, ousando para o futuro, na formação de uma elite científico-cultural de alto nivel, como unica forma de aspiração à posição de grande País. 


\section{OBJETIVOS DA PÓS-GRADUAÇÃO}

o objetivo fundamental do sistema de pós-graduação organizado é o processo da formação de professores, de pesquisadores e cientistas, bem como o treinamento de graduados para solucionar problemas decorrentes da complexidade da sociedade moderna. O próprio enunciado dos objetivos desse sistema educacional de alto nivel já o define como um sistema de pesquisa e de formação de professores de nivel acadêmico, diferente do sistema de educaçz̃o profissional de graduados, embora não o dispense como base e pré-requisito. Em outras palavras, a pós-graduação dentro da filosofia original alemã, adotada pela Universidade americana, visa criar uma elite cientifico-cultural criativa de "pensadores", pesquisadores e professores de alto nivel para a solução de novos problemas, enquanto que a educação profissional de graduados visa o aperfeiçoamento e a especialiazção de uma base executiva de nivel superior para o exercicio profissional.

o conceito literal de pós-graduação seria todo estudo sistematizado realizado por graduado no seu respectivo campo de atuação. Ora, se ao pé da letra a definição está correta, como doutrina é absolutamente falha e imprecisa, bastando para verificarmos esta incoerência $a$ análise dos objetivos da especializaçâo $e$ do doutorado: o primeiro visa o aperfeiçoamento profissional, enquanto o doutorado destina-se à seleção de elites científico-culturais. Criou-se então a terminologia de pćs-graduação "sensu lato", acredito que para definir o todo e pósgraduação "rensy stficto" para definir a pós-graduação em seu sentido original, isto e, o P ( agora acrescido da inovaçáo anglo-americana - o "master", traduzido para o ncsso meio como "mestre" $e$ incorporado à pós-graduaçâo "stricto sensu". Felo menos duas controvérsias nasceram dentro do "novo" sistema de pós-graduaçâa entre nós: a primeira é sobre a validade do mestrado na pós-graduação "sensu stricto" e a segunda é sobre o doutorado na pós-graduação profissional, sobretudo na área médica, uma vez que, por definişão e doutrina, o PhD é um pesquisador eminentemente de área básica.

Acreditamos que um "modelo brasileiro" de pós-graduação senso amplo possa vir a ser empregado com sucesso em nosso meio, desde que adotado como "sistema" e não como curso isolado, no qual a especialização forma base para o mestrado e este para o doutorado, com flexibilidade horizontal em cada fase, porém com escalonamento vertical em profundidade e com alto poder seletivo. A adoção de um sistema dessa natureza poderia, a nosso ver. harmonizar a pós-graduação profisional como uma etapa prévia aos graus acadêmicos sem perda do pragmatismo, da flexibilidade e da profundidade exigidos pelo sistema. Em nenhum outro lugar cabe mais do que aqui a frase "adapte, ño adote", principalm:nte no campo da pós-graduação onde a experiência brasileira é extremamente redu¿ida, havendo uma natural tendêncix para a adoçâo pura e simples de sistemas experimentados em outros paises, porém sem a menor possibilidade de ôxito no nosso, de infra-estrutura material e humana completamente diferentes.

Tradicionalmente a formação do Professor de Medicina em nosso meio sempre foi de duração longa e vivida, começando no internato, continuando na residência e decidindo-se finalmente no decurso da especialização, quando o candidato a professor "encosta-se" numa Disciplina voluntariamente ou como "bolsista" para, ao final de um periodo variável, de acordo com o seu desempenho $e$ com as oportunidades, vir a ser "honrado" com um convite do Professor ou do Chefe do Serviço para auxiliar nas aulas práticas. Passa-se um longo periodo de expectativa, até que se oficializa a situação do novo auxiliar. Surgem os primeiros trabalhos, capengas, porém cheios de esperanças; um prurido imenso de escrever invade a alma do jovem professor que, ao ver seu nome e as suas letras publicados na "Folha Médica" e no "O Hospital", enche-se de orgulho e de uma vaidade incontida. Uma lei o promove a Assistente. Vem a oportunidade de uma viagem ao exterior. Muita meditação e a volta com uma explosão de entusiasmo reformista. As dificuldades de pesquisa e as decepções. 
A critica. A realização da "tese" e o concurso de "Docência Livre". Ele é agora um professor maduro; desenvolve o espirito de competição à procura do que pensa ser "um lugar ao sol". Este é o Professor de minha época, apurado no cadinho das dificuldades, imperfeito, muito imperfeito, porém forte è experiente porque foi treinado no trabalho.

\section{Senhores,}

Temos agora a oportunidade de uma seleção organízada através dos cursos de mestrado e doutorado, porém não nos iludamos que um "Mestre" pọsa ser formado por um simples curso de dois anas ou que um "Doutor Pesquisador" seja feito por força de matrícula ou aprovação em cursos. Não se improvisa um Professor, não se "cria" um Pesquisador. Acredito nos cursos de mestrado e doutorado como oportunidade de aprendizado e forma de seleção. Acredito na seleção indiv:dual e na critica como ensinamento. Haverá pós-graduação onde houver um Chefe de Escola e um líder da pesquisa.

\section{POS-GRADUACAOO NA MEDICINA TROPICAL}

Ao conceituarmos Medicina Tropical, definimo-la como uma especialidade de atividade de campo, hospitalar e laboratorial, ponto de junção entre a clinica, a parasitologia, a microbiologia, a patologia e o meio ambiente. Dentro dessa linha de idéias, qualquer programa de pós-graduação nessa área deverá incluir obrigatoriamente os ramos mencionados e os seus desdobramentos. O estudo da ecologia e da epidemiologia proporcionam ao aluno uma abertura para os problemas do meio ambiente e de sua importância no desenvolvimento da patologia tropisal. A estatística e a introdução ao estudo da metodologia científica estabelecem o senso da medida dos fenômenos, indispensável ao pesquisador e professor, que utilizam, constantemente a critica como ensinamento, testando as "verdades" estabelecidas e descobrindo outras verdades em sua atividade criadora. $O$ desenvolvimento do senso de indagação e de comprovação experimental deve ser ponto culminante dos objetivos de qualquer programa de pós-graduação "sensu stricto". O vocabulário do estudante deve ser rico das indagações - porque, quando, como e onde - e o seu espirito deve ser impregnado da curiosidade $e$ do desejo de respondê-las experimentalmente. Os mais simples problemas devem ser respondidos e comprovados cientificamente. Se me perguntassem a diferença entre o estudante de graduação e de pós-graduação em Medicina Tropical, diria que o primeiro responde pela prática e pela informação $e$ que o último responde pela critica e pela experimentação.

\section{a) Seleção dos candidatos}

Este é certamente o ponto crucial e mais dificil de toda a pós-graduação, inicialmente porque a maioria dos candidatos e grande parte dos professores confunde pós-graduação com aperfeiçoamento e especialização profissional. Por outro lado, a deficiência dos cursos de graduação com a massificação do ensino nas escolas profissionais $e$ a criação de novas escolas, com corpo docente fraco e inexperiente, entrega ao mercado de pós-graduação uma massa de estudantes mal formados, que em busca de melhorar os conhecimentos que não puderam obter na graãuação, procuram os cursos de pós-graduação, meio atarantados à procura de uma bolsa de estudos para o $7^{\circ}$ ano como tábua de salvação, enquanto se organizam para enfrentar a vida profissional. Esta é certamente a principal causa da desistência ou abandono dos cursos de pós-graduação pelos alunos, sobretudo na fase de realização das "Teses", quando descobrem a sua total falta de preparo e vocação para a carreira docente e de pesquisa.

Em nossa experiência a melhor forma de seleção é a entrevista, quando se pode discutir com o candidato a sua experiência, o seu curriculo e os seus objetivos para o futuro, e aquilatar o seu grau de percepção e potencialidade para a carreira docente e de pesquisa. Estabelecemos algumas prioridades para a selesão: 
19) Candidatos que já estejam exercendo o magistério e/ou desenvolvendo linhas de pesquiza em Medicina Tropical ou em áreas correlatas.

29) Candidatos com residência em Clínica Médica ou em Doenças Infecciosas e Parasitárias e/ou com experiência de epidemiologia de campo em Medicina Tropical, de laboratório de parasitologia, entomologia etc.

39) Internos de Serviços de Doenças Infecciosas e Parasitárias qualificados, que demonstrem excepcional interesse pela pesquisa e que desejem filiarse à atividade docente.

49) Candidatos procedentes de áreas prioritárias, Norte, Nordeste e CentroOeste do Brasil, principalmente aqueles que desejem filiar-se às Universidades locais.

59) Estrangeiros que possam observar e propagar os conhecimentos aqui adquiridos e miscigenar os seus conhecimentos e experiência de vida com os estudantes brasileiros.

$\left.6^{\circ}\right)$ A pessoa do candidato, sua inteligência, sua cultura geral, seu caráter e sua sanidade física e mental.

b) Desenvolvimento do Curso

1. Seminários e discussōes

Esta é a forma mais válida a nosso ver para o aprimoramento científicocultural do aluno de pós-graduação, pois de um lado lhe dá a oportunidade de buscar por si mesmo a informação disponivel na literatura médica, metabolizá-la pela crítica e pela meditação e apresentá-la de forma pública para os seus colegas e observadores, obrigando-se a estudar dentro de uma autodisciplina intelectual $e$ a receber as criticas $e$ observaçōes, que aos poucos vão se incorporando à sua personalidade de professor e futuro perquisador. Temos utilizado este método com grande sucesso: os alunos recebem com antecedência uma série de cerca de 40 temas anuais para discutirem um por semana, no primeiro ano do curso. Ao final de cada semana, depois de uma extensa revisão bibliográfica sobre o assunto $e$ de terem debatido entre si, 4 a 6 alunos apresentam o tema em forma de seminário público, onde recebem as criticas, observaçóes e perguntas dos professores, colegas e alunos presentes. Esta forma de apresentação, além de estimular o aluno ao estudo aprofundado dos temas, proporciona-lhes um grande desembaraço de exposição, servindo-lhes também como treinamento didático.

\section{Treinamento clínico}

Parece-nos da mais alta importância para o "Tropicalista" uma formação clínica global, com ênfase nas doenças infecciosas e parasitárias em seus múltiplas e variaaos aspectos. Deve ser realizado dando-se responsabilidade aos pós-graduandos nas enfermarias, ambulatórios, na apresentaçāo dos casos clínicos de sua responsabilidade e na orientação dos internos $e$ estudantes sob sua supervisão. Dois anos de experiência num Serviço de bom movimento e elevado nivel são suficientes para desembaraçar um aluno diligente $e$ aplicado.

\section{Treinamento em laboratório}

Além dos cursos de parasitologia, entomologia e microbiologia é necessário que o aluno adquira desembaraço nas técnicas básicas de laboratório e de experimentação animal, a fim de que possa desenvolver-se com maior profundidade em uma delas, quando do desenvolvimento experimental de sua tese, no assunto particular que houver escolhido. E importante que o aluno 
adquira um bom conhecimento de citologia, das técnicas de coloração, do manejo das chaves entomológicas e dos meios de preservação de espécimens para exame posterior, além naturalmente da facilidade de reconhecimento morfológico dos elementos parasitários, em sangue, fezes, urina e nos tecidos. Enfim, o "Tropicalista" deve ser familiarizado com o laboratório, para execução das técnicas convencionais e aberto ao aprendizado das técnicas mais sofisticadas num campo particular de pesquisa por que venha a se interessar.

\section{Treinamento de campo}

o que melhor define um "Tropicalista" é a sua experiência de campo, uma vez que os clínicos e parasitologistas puros quase sempre se restringem $\dot{a}$ atividade hospitalar e laboratorial, respectivamente. Partindo do principio de que o hospital é o lugar menos indicado para se estudar uma doença, embora seja o melhor lugar para se estudar um doente, uma vez que a amostra hospitalar é sempre viciada, é necessário que o "Tropicalista" seja eminentemente um pesquisador de campo, para que possa definir a história natural da doença e da infecção, abordando doentes $e$ não doentes, numa visäo global, clínica, ecológica e epidemiológica. Um treinamento intensivo de pelo menos 4 semanas no campo, desenvolvendo um modelo de investigação epidemiológica, é indispensável em qualquer curso de pós-graduação em Medicina Tropical.

\section{c) Araliação final}

A avaliação final é quase tão difícil como a seleção inicial. Os exames parciais obrigatórios, bem como os exames finais, dificilmente medem a potencialidade do futuro professor e pesquisador. Um ano de observação no Curso-base tem se mostrado insuficiente para julgamento preciso. Muitas vezes um candidato que fez um curso fraco ou regular revela-se um excelente planejador ao apresentar o seu plano de tese. Outras vezes, o aluno brilhante durante o curso embaraça-se no plano de tese e não consegue apresentar nada aceitável e termina desistindo frente a dificuldades de desenvolvimento de um plano de pesquisa.

\section{d) Desenvolvimento da Tese}

A tese de mestrado deve constar de uma monografia de casuistica própria e experiência pessoal do candidato, na qual ele tem oportunidade de demonstrar a sua capacidade de organização de um trabalho, que embora não necessariamente original, demonstre o seu amadurecimento para organizar uma pesquisa e ordená-la de forma didática e compreensiva, a fim de que possa tirar conclusões cientificamente válidas. Necessariamente deverá ser um trabalho simples $e$ objetivo, para que seja exequivel neste nivel. Já a tese de doutorado deve ser um trabalho de pesquisa original, que traga uma real contribuição científica $e$ que demonstre o amadurecimento do candidato como pesquisador de alto nivel e um perfeito manejo da metodologia científica.

\section{e) Treinamento didático}

o treinamento didático deve ser realizado ao longo do curso, no $2^{\circ}$ e $3^{\circ}$ anos, após a conclusão do curso-base, quando o aluno deverá ser colocado como auxiliar de ensino do curso de graduação. Esta colocação terá uma tríplice vantagem: 10) o aluno pós graduando terá a oportunidade de continuar estudando pela solicitação constante no preparo das aulas; 29) o treinamento será realizado no próprio trabalho, de forma prática e objetiva e sob supervisão de pro- 
fessores mais experientes; 39) proporcionará uma substancial ajuda ao corpo docente da Instituição, em geral muito sobrecarregado com a massificação do ensino de graduação.

\section{UMA EXPERIENCIA DE PÓS-GRADUAÇAO EM MEDICINA TROPICAL}

Hả 4 anos vimos realizando, aparentemente com sucesso, pelo menos no que nos foi dado observar até agora, um curso de pós-graduação "stricto sen'u" em Doenças Infecciosas e Parasitárias, no Departamento de Medicina Preventiva da Faculdade de Medicina da Universidade Federal do Rio de Janeiro.

o curso vem se realizando de forma escalonada, com a duração minima de 1,2 ou 3 anos caso o candidato deseje obter a Especialização, o Mcstrado ou o Doutorado, e com a duração máxima de 5 anos. No primeiro ano podem ser matriculados até 12 alunos que exercem atividades clínicas no periodo da manhã e obtêm os créditos em nível de pós-graduaçâo, sob a forma de cursos, seminários e prát:cas de laboratório na parte da tarde, em regime intensivo de 40 horas de trabalhos semanais. Ao final de um ano, os alunos realizam um trabalho de campo com a duração de 4 semanas e submetem-se a um exame final. Se aprovados com média igual ou superior a $7(R)$, nas provas, seminários e "observação continua", são considerados aprovados e podem receber certificado de Especialização pela Universidade.

Dos aprovados no curso de Especialização afé o número de 6 podem ser inscritos para o Mestrado. Neste periodo, além das matérias da "área de concentração", os alunos desenvolvem a Tese de Mestrado e recebem o treinamento didático, como auxiliares de ensino do curso de Graduação durante 1 a 2 anos. Dos candidatos aprovados no "Mestrado", pretendemos que sejam selecionados até $50 \%$ para desenvolverem a "Tese de Doutorado", em periodo adicional de 1 a 2 anos, tese esta que se exige original e de alto conteúdo científico, geralmente realizado com a colaboração de um laboratório ou disciplina de área básica. Estes últimos, são, a nosso ver os candidatos a professores e pesquisadores de alto nível. 